\title{
Formação ferrífera associada à sedimentação glaciogênica da Formação Puga (Marinoano) na Serra da Bodoquena, MS
}

\author{
Thiago Piacentini', Paulo César Boggiani², Jorge Kazuo Yamamoto², \\ Bernardo Tavares Freitas ${ }^{3}$ \& Ginaldo Ademar da Cruz Campanha ${ }^{4}$
}

\begin{abstract}
Resumo No presente artigo descreve-se ocorrência de formação ferrífera associada a diamictitos da Formação Puga (Marionano) em contexto geológico diferente das formações ferríferas do Grupo Jacadigo, no Maciço de Urucum. A formação ferrífera ocorre em camada de $2 \mathrm{~m}$ de espessura, de direção NS, com mergulho de $45^{\circ} \mathrm{E}$, e encontra-se associada a diamictito de matriz ferruginosa, foliado e com metamorfismo de baixo grau. Apresenta bandamento centimétrico com camadas de hematita e magnetita alternadas com camadas submilimétricas de sílica, em parte estiradas devido às deformações tectônicas da Faixa Paraguai. Os teores de $\mathrm{Fe}_{2} \mathrm{O}_{3}$ variam da ordem de $75 \%$, na base e no topo do pacote, para 52\% nas porções intermediárias da seção. A concentração do teor de Fe nas bordas se dá pela remobilização da sílica para o centro do corpo devido, provavelmente, à ação tectônica. Análises químicas mostram que os teores de $\mathrm{Al}_{2} \mathrm{O}_{3}$ são altos $(2,89-3,45 \%)$ e a forte correlação com $\mathrm{TiO}_{2}$ e $\mathrm{Zr}$ indicam contribuição de componentes terrígenos nos sedimentos predominantemente químicos. Blocos isolados de granito ocorrem na formação ferrífera, mas a ação tectônica dificulta a observação das relações entre os clastos e o bandamento original. Apesar da Formação Puga ter sua origem relacionada a eventos glaciogênicos, não foram encontradas evidências seguras que permitissem relacionar a origem desta formação ferrífera a processos glaciais.
\end{abstract}

Palavras Chave: formação ferrífera, Formação Puga, glaciação, Marinoano, Faixa Paraguai.

\begin{abstract}
Iron formation associated with the glaciogenic deposits of the Puga Formation (Marinoan) in the Serra da Bodoquena, Mato Grosso do Sul, Brazil. Iron formation associated with diamictite interpreted as belonging to the Puga Formation (Marinoan) is reported here in a different context from the already known deposits of the Jacadigo Group, at the Urucum's Massif. The iron formation occurs as a bed about $2 \mathrm{~m}$ thick, oriented NS and dipping $45^{\circ}$ to East, confined in a massive foliated diamictite with ferruginous matrix presenting low metamorphism. It's composed of centimetric hematite and magnetite layers alternated with submilimetric layers of silica, sometimes stretched due to the tectonic deformation of the Paraguay Mobile Belt. $\mathrm{Fe}_{2} \mathrm{O}_{3}$ vary from $75 \%$ in the borders, to $52 \%$ in the center of the body. The iron concentration in the borders is due to the remobilization of silica to the center of the body, probably because of the tectonic events. Chemical analyses show that $\mathrm{Al}_{2} \mathrm{O}_{3}$ concentrations are high $(2,89-3,45 \%)$, and the strong linear correlation with $\mathrm{TiO}_{2}$ and $\mathrm{Zr}$ indicate terrigenous contribution during chemical deposition. Isolated blocks of granite occur within the BIF, but tectonic overprinting makes it difficult to have a clear observation of the relationship between the clasts and original lamination. Despite the Puga Formation has its origin related to glaciogenic events, there are no clear evidence to link this iron formation origin to the glacial processes.
\end{abstract}

Keywords: iron formation, Puga Formation, glaciation, Marinoan, Paraguay Mobile Belt

INTRODUÇÃO Formações ferríferas Pré-Cambrianas, conhecidas genericamente como formações ferríferas bandadas (Banded Iron Formation - BIF), são únicas ao longo do registro sedimentar, face aos processos de formação (não atualísticos) e às potencialidades minerais.

É de consenso geral que a maior concentração deste tipo de deposição situa-se entre unidades arqueanas e paleoproterozóicas, sem ocorrência após 1,8 G.a, com exceção dos depósitos do final do
Neoproterozóico, geralmente associados a sucessões sedimentares com influência glacial (Fig. 1). Exemplos desta associação encontram-se no Grupo Rapitan no noroeste canadense (Young 1976), Grupo Umberatana na Austrália (Trendall 1973), Supergrupo Damara na Namíbia (Beukes 1973), Grupo Jacadigo no Maciço de Urucum (Dorr II 1945, Almeida 1946). A importância destas associações aumentou recentemente devido às implicações para o entendimento das mudanças globais que ocorreram durante as glaciações neoproterozóicas.

1 - Pós-Graduando no Programa de Recursos Minerais, Instituto de Geociências, Universidade de São Paulo, São Paulo, SP, Brasil. E-mail: tptini@yahoo.com.br

2 - Instituto de Geociências, Universidade de São Paulo, São Paulo, SP, Brasil. E-mails: boggiani@usp.br, jkyamamo@usp.br

3 - Pós-Graduando Programa de Geotectônica, IGc, Universidade São Paulo, São Paulo, SP, Brasil. E-mail: bernardo_tf@yahoo.com.br

4 - Instituto de Geociência, Universidade de São Paulo, São Paulo, SP, Brasil. E-mail: ginaldo@usp.br 


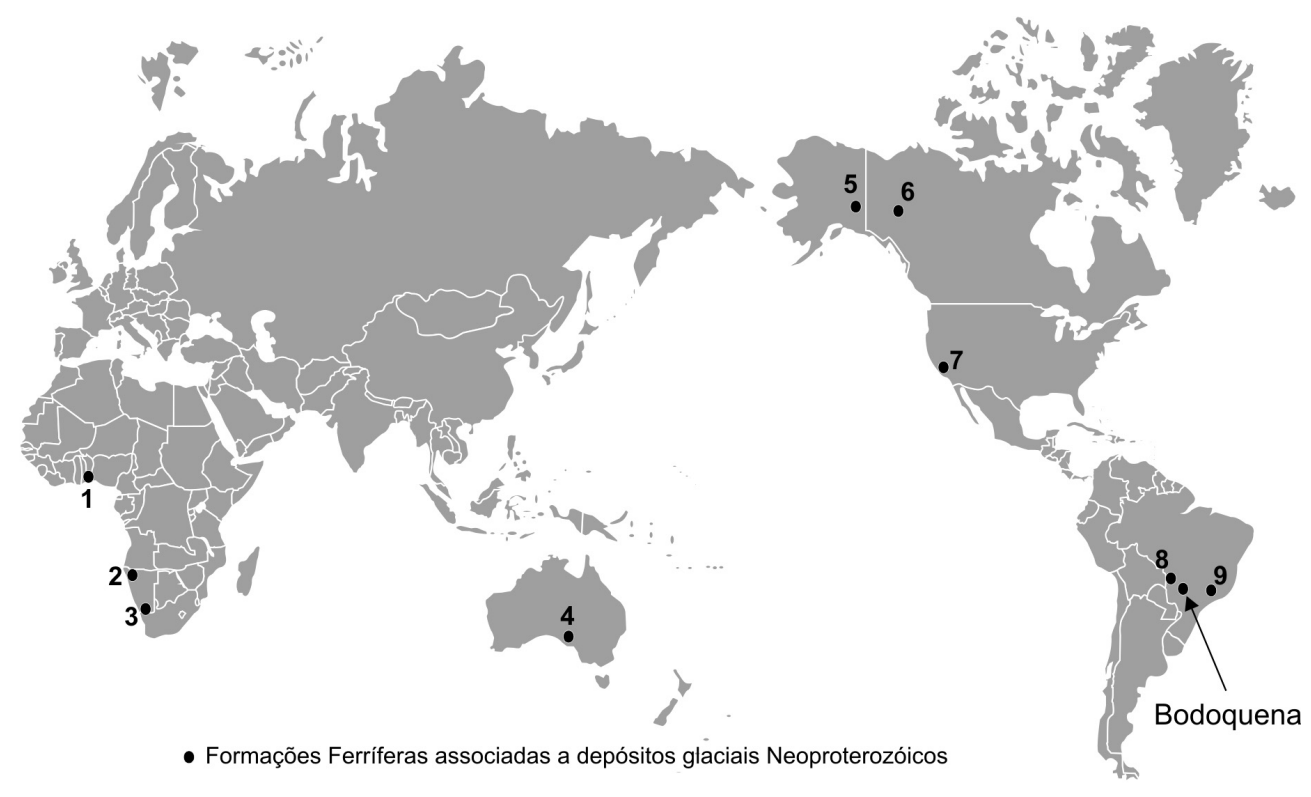

Figura 1 - Localização de formações ferríferas associadas a depósitos glaciais do Neoproterozóico (Adaptado de Yeo 1986). A seta marca o local da ocorrência na Formação Puga, na Serra da Bodoquena, MS, descrita neste trabalho; 1 - Grupo Bisokpabe, Togo (Trompette 1981); 2 - Formação Chuos, Namíbia (Beukes 1973); 3 - Formação Numees, Namíbia e África do Sul, do Supergrupo Damara (Beukes 1973, Martin 1978); 4 - Subgrupo Yudnamutana, Sul da Austrália (Delgarno \& Johnson 1965); 5 - Grupo Tindir, leste do Alasca (Young 1982); 6 - Grupo Rapitan, Canadá (Young 1976); 7 - Formação Kingston Peak, Califórnia - EUA (Miller 1985); 8 - Grupo Jacadigo no Maciço de Urucum, Corumbá - MS (Dorr II 1945); 9 - Grupo Macaúbas, Porteirinha-MG (Vilela 1986).

O presente artigo tem por objetivo apresentar descrição de ocorrência de formação ferrífera associada à sedimentação glaciogênica da Formação Puga, anteriormente notificada por Boggiani et al. (2006) e Piacentini et al. (2006). Esta ocorrência foi descoberta na Fazenda São Manoel (20³9'18.81'S / 56³6'20.47’W) e situa-se ao sul da cidade de Bodoquena, em Mato Grosso do Sul.

A formação ferrífera da Fazenda São Manoel situa-se em posições estratigráficas superiores da Formação Puga, no contexto da Faixa de Dobramentos Paraguai, em situação geológica distinta das amplamente conhecidas formações ferríferas do Grupo Jacadigo, no Maciço de Urucum, onde ocorrem aproximadamente $300 \mathrm{~m}$ de BIF sobre depósitos siliciclásticos arcoseanos de centenas de metros (Dorr II 1945, Almeida 1946).

CONTEXTO GEOLÓGICO E DESCRIÇÃO DA OCORRÊNCIA Existem diversas propostas de subdivisão das unidades estratigráficas da Faixa Paraguai e de suas respectivas coberturas cratônicas. Alvarenga \& Trompette (1992) apresentaram proposta na qual individualizaram uma unidade inferior, formada por sedimentos glácio-marinhos (Formação Puga) com turbiditos distais, os quais seriam correspondentes aos metassedimentos do Grupo Cuiabá. Esta unidade inferior seria recoberta por rochas carbonáticas (grupos Corumbá e Araras) e, na porção setentrional da Faixa Paraguai, uma unidade superior, siliciclástica, correspondente ao
Grupo Alto Paraguai (Fig. 2).

Atribui-se a deposição da Formação Puga ao evento glacial Varangeriano/Marinoano (Alvarenga \& Trompette 1992, Alvarenga et al. 2000, Alvarenga et al. 2004), com duração de 620 a $600 \mathrm{Ma}$ (Kendall et al. 2004). Porém, até o presente momento, não há datação radiométrica que possibilite comprovar esta correlação. Interpreta-se a idade marinoana para a Formação Puga de forma indireta em função dos diamictitos serem sobrepostos por calcários da Formação Tamengo (Grupo Corumbá) que contém os fósseis metazoários Cloudina e Corumbella (Hahn et al. 1982, Zaine \& Fairchild 1987), de idade ediacarana, além de intercalações de tufos vulcânicos, com idade por volta de 545 Ma obtida pela datação de zircões (Boggiani et al. 2005).

Na região da Serra da Bodoquena, ocorrem sedimentos interpretados como glácio-marinhos e como turbiditos com influência glacial correspondentes à Formação Puga. Esta é recoberta pelo Grupo Corumbá que marca o fim da influência glacial e a subida do nível do mar e inclui unidades siliciclásticas e carbonáticas alternadas atingindo uma espessura de aproximadamente $600 \mathrm{~m}$ (Almeida 1965, Boggiani 1998) (Fig. 3). Este grupo possui, da base para o topo, as formações Cadiueus, representada por um espesso pacote conglomerático, interpretada como depósitos de leques aluviais sin-tectônicos durante a abertura da bacia Corumbá; Cerradinho, composta por conglomerados, are- 


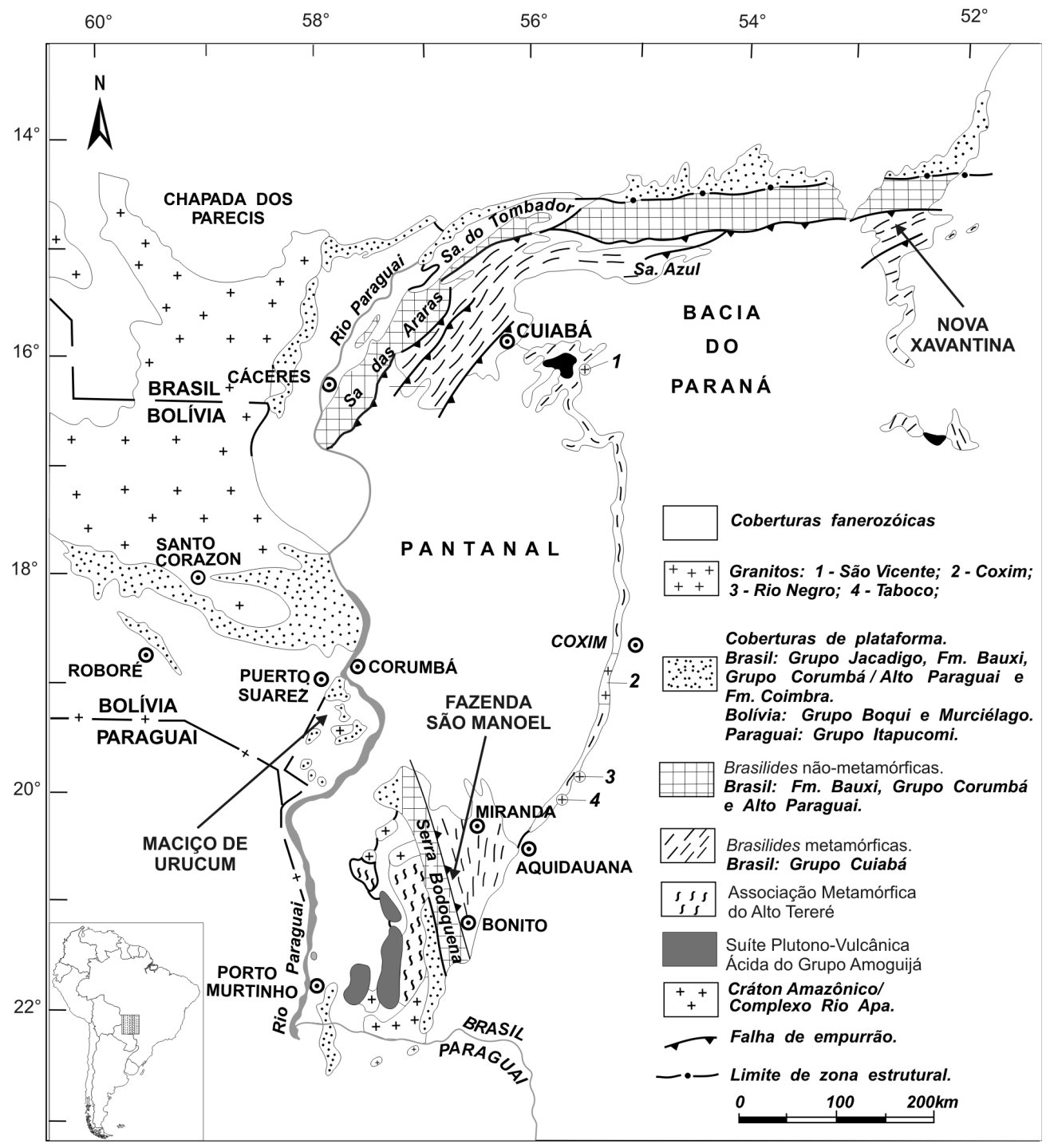

Figura 2 - Mapa geológico da Faixa Paraguai indicando, através das flechas, as ocorrências de formações ferríferas de Nova Xavantina, Maciço de Urucum e São Manoel (estudada no presente trabalho. Mapa modificado de Alvarenga et al. 2000).

nitos e pelitos; Bocaina, constituída por carbonatos dolomíticos de águas rasas ricos em estromatólitos com grande variação faciológica lateral incluindo fosforitos; Tamengo, formada por calcários e pelitos carbonosos interpretados como depósitos de águas profundas, e a Formação Guaicurus composta por siltitos acinzentados, que marcam o final da deposição na bacia Corumbá. As unidades presentes encontram-se deformadas com falhamentos inversos e dobras isoclinais, denotando vergência tectônica para oeste.

No local da ocorrência da formação ferrífera (Fazenda São Manoel) e em núcleos de anticlinais, a sudoeste dessa ocorrência, afloram corpos extensos de diamictitos com matriz arenosa a argilosa, com clastos de tamanhos, formas e litologias variadas que não chegam a compor $20 \%$ da rocha. No núcleo do anticlinal da Fazenda Santa Terezinha (2053'18.69's / $\left.50^{\circ} 40^{\prime} 14.54^{\prime \prime} \mathrm{W}\right)$ ocorre um bloco anguloso de $1,5 \mathrm{~m}$ de gnaisse (Fig. 4) e blocos decimétricos de granito. No topo dos diamictitos observa-se uma camada de dolomito, de $3 \mathrm{~m}$ de espessura, de cor marrom clara a branco, laminada, possível representante de capa carbonática pós-glacial, como observado no topo da Formação Puga no Morro do Puga (Boggiani \& Coimbra 1996, Boggiani et al. 2003) e em Mirassol do Oeste (Nogueira et al. 2003, Trindade et al. 2003, Alvarenga et al. 2004).

A formação ferrífera da Fazenda São Manoel ocorre como camada única de $2 \mathrm{~m}$ de espessura, atitude NS, $45^{\circ} \mathrm{E}$, limitada, por contato brusco, no topo e na base por um diamictito de matriz ferruginosa (Fig. 5) com aproximadamente $35 \%$ de $\mathrm{Fe}_{2} \mathrm{O}_{3}$. Exposição de diamictito semelhante, com matriz ferruginosa, observa-se desde a Fazenda Paredão, situado a cerca de $10 \mathrm{~km}$ ao sul da ocorrência, até a Fazenda Potreiro, a cerca de $20 \mathrm{~km}$ a norte da Fazenda São Manoel. Mapeamentos geológicos identificaram estes metassedimentos como pertencentes ao Grupo Cuiabá (Corrêa et al. 1979, Nogueira et al. 1978, Godói 2001) e foram redefinidos como pertencentes à Formação Puga (Lacerda 


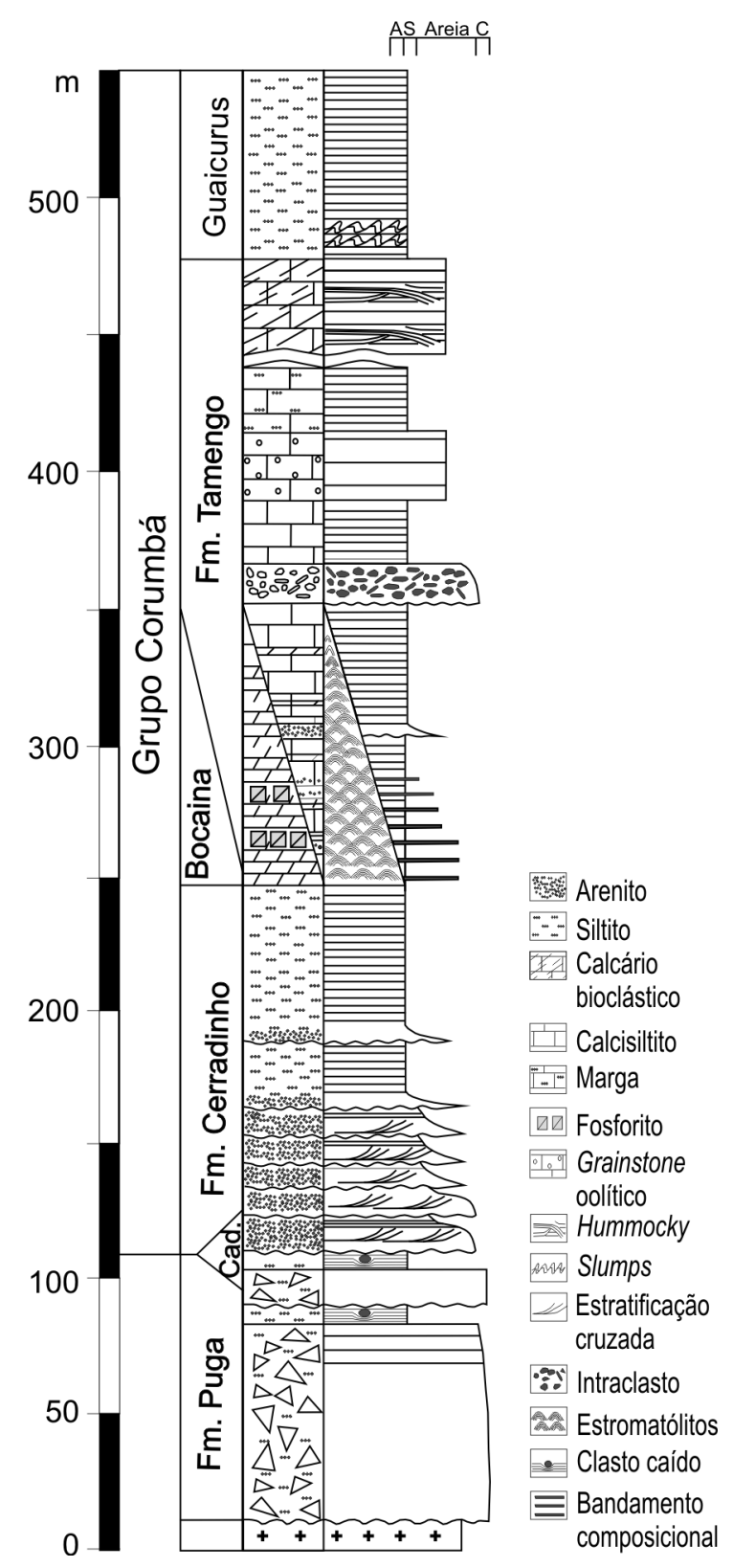

Figura 3 - Coluna estratigráfica mostrando a Formação Puga e o Grupo Corumbá. Cad: Formação Cadiueus (modificado de Gaucher et al. 2003).

Filho et al. 2006).

Os metadiamictitos da Formação Puga, na área de ocorrência, são de matriz cinza esverdeada, pelítica, e apresentam xistosidade, por vezes, crenulada. Clastos de quartzito e gnaisse, centimétricos a decimétricos, perfazem cerca de $15 \%$ e estão geralmente estirados em função das deformações tectônicas. A matriz desta rocha grada para uma composição rica em magnetita/ hematita (Fig. 6) até o contato brusco com a formação ferrífera (Fig. 7).

Ainda no contexto da Faixa Paraguai há a ocorrência das formações ferríferas do Grupo Jacadigo, no Maciço de Urucum, em Corumbá (MS). Trompette et al. (1998) questionaram a interpretação de origem gla-

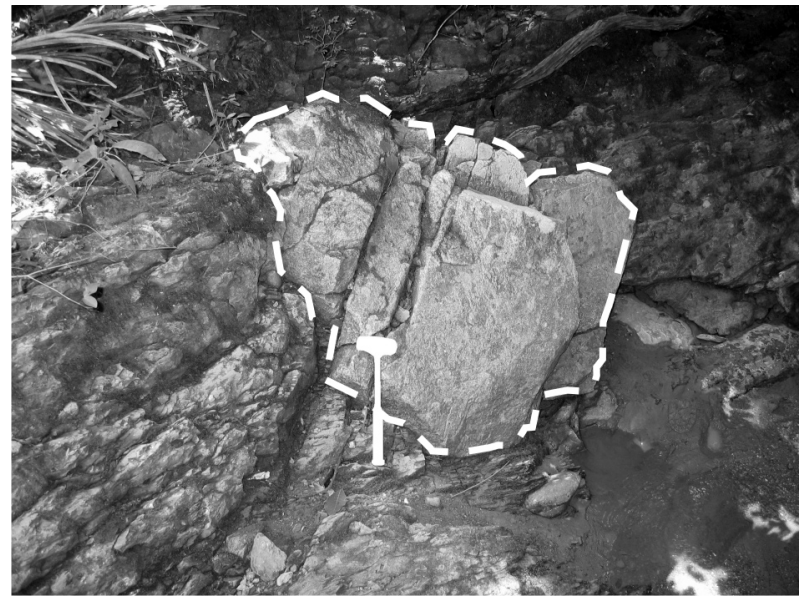

Figura 4 - Fotografia de bloco anguloso de gnaisse com cerca de 1,5 $m$ de diâmetro (circundado pela linha pontilhada) imerso em diamictito de matriz areno-argilosa.

cial (Urban et al. 1992) desta ocorrência pelos clastos isolados nos BIFs, que chegam a atingir dimensões métricas, poderem ser resultado de fluxo de detritos associados a turbiditos, já que a deformação na laminação abaixo dos clastos é ausente, e porque todos os blocos são aparentemente derivados do embasamento granítico exposto próximo ao Maciço de Urucum. Existem também referências sobre formações ferríferas no Grupo Cuiabá, na porção setentrional da Faixa Paraguai, nas regiões de Poconé (Da Rosa et al. 1997), associado a sedimentos, possivelmente, equivalentes a porções distais da Formação Puga, e em Nova Xavantina, associado a uma seqüência metavulcano-sedimentar (Pinho 1990, Dantas \& Martinelli 2003) (Fig. 2).

MÉTODOS ANALÍTICOS Foram realizadas análises petrográficas e químicas no intuito de se caracterizar química e mineralogicamente a ocorrência de formação ferrífera da Fazenda São Manoel. Para as análises, realizou-se coleta sistemática de amostras em uma trincheira, da base até o topo do pacote de BIF, a intervalos de aproximadamente 15 centímetros, incluindo o diamictito com matriz ferruginosa.

Foram realizadas análises petrográficas por microscopia óptica (luz refletida e transmitida) e microscopia eletrônica de varredura (MEV) em equipamento LEO 440I, com recobrimento das amostras com carbono pela máquina evaporadora Emitech K250. Análise por difratometria de raios X em amostras de pó foram efetuadas em equipamento Siemens D5000, operando a $40 \mathrm{kV}$ e $40 \mathrm{~mA}$ com $2 \theta$ entre 3 e $65^{\circ}$, em passos de $0,05^{\circ}$ e 1s/passo, sendo utilizada a radiação $\mathrm{Cu}-\mathrm{K} \alpha$. Utilizouse o banco de dados JCPDS-ICDD para interpretação dos difratogramas.

Análises químicas de rocha total foram realizadas por fluorescência de raios X (Philips Analytical PW 2400) em pastilhas fundidas e prensadas para os elementos maiores e menores $\mathrm{SiO}_{2}, \mathrm{Al}_{2} \mathrm{O}_{3}, \mathrm{MnO}, \mathrm{MgO}$, $\mathrm{CaO}, \mathrm{Na}_{2} \mathrm{O}, \mathrm{K}_{2} \mathrm{O}, \mathrm{TiO}_{2}, \mathrm{P}_{2} \mathrm{O}_{5}, \mathrm{Fe}_{2} \mathrm{O}_{3}$ e os elementos tra- 

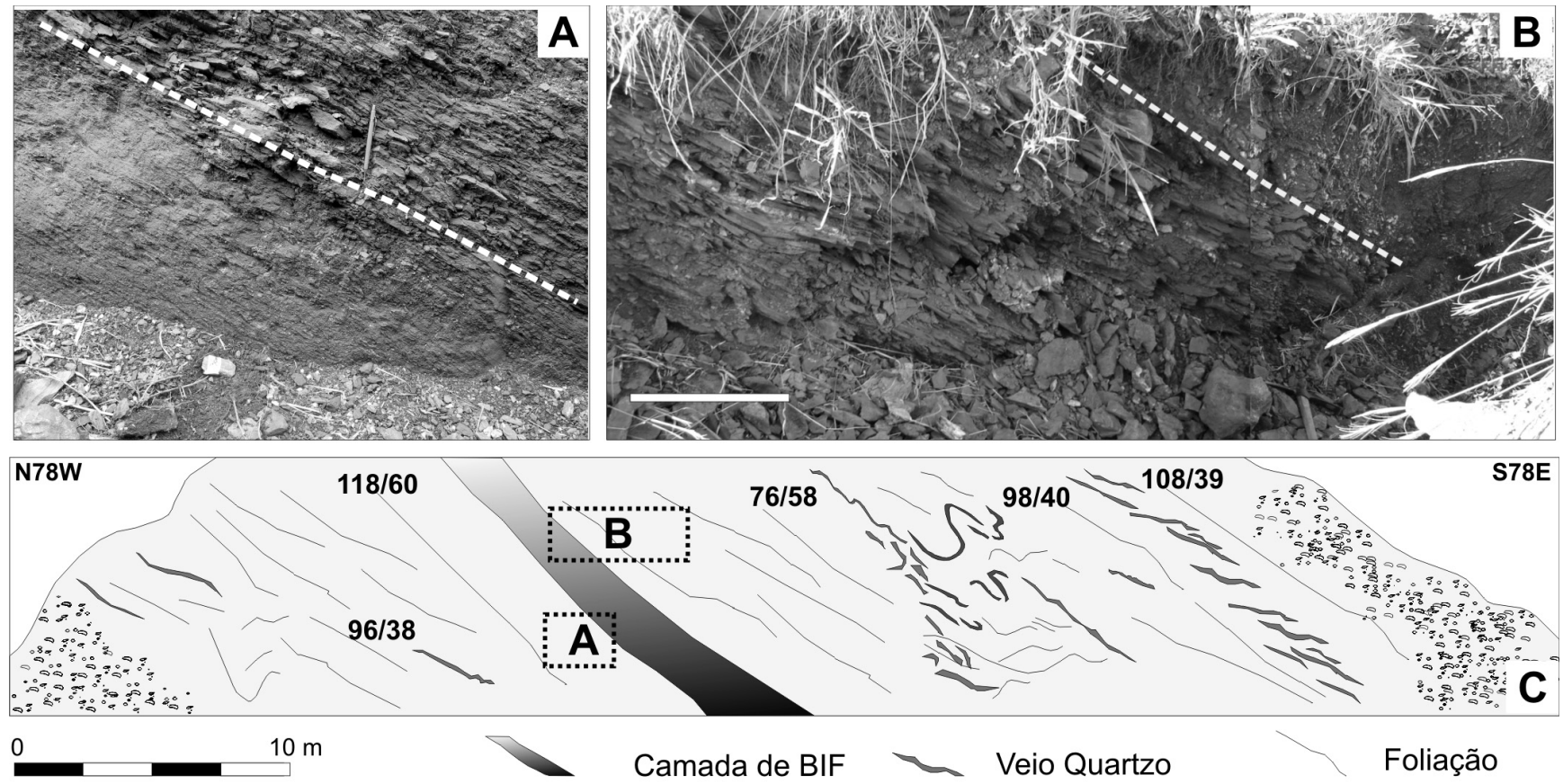

Exagero vertical $5 X$
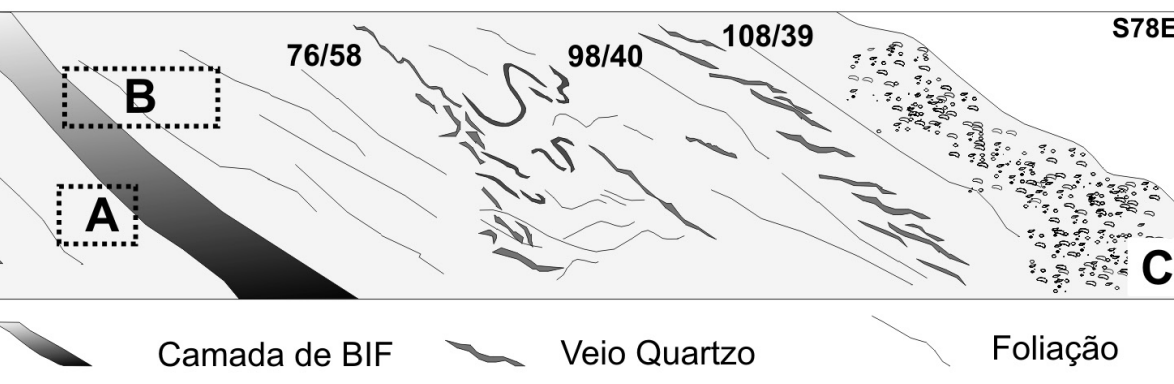

Foliação

Diamictito

Colúvio

98/40 Atitude

Figura 5 - Exposição, em trincheira, da formação ferrifera. A) Contato do diamictito de matriz ferruginosa (abaixo da linha tracejada) com a camada de BIF; B) Contato do diamictito de matriz ferruginosa (acima da linha tracejada) com a camada de BIF - escala $0,5 \mathrm{~m}$; C) Esquema simplificado da trincheira aberta na Fazenda São Manoel onde é possível observar a camada de BIF: A e B indicam as posições das fotos A e B.

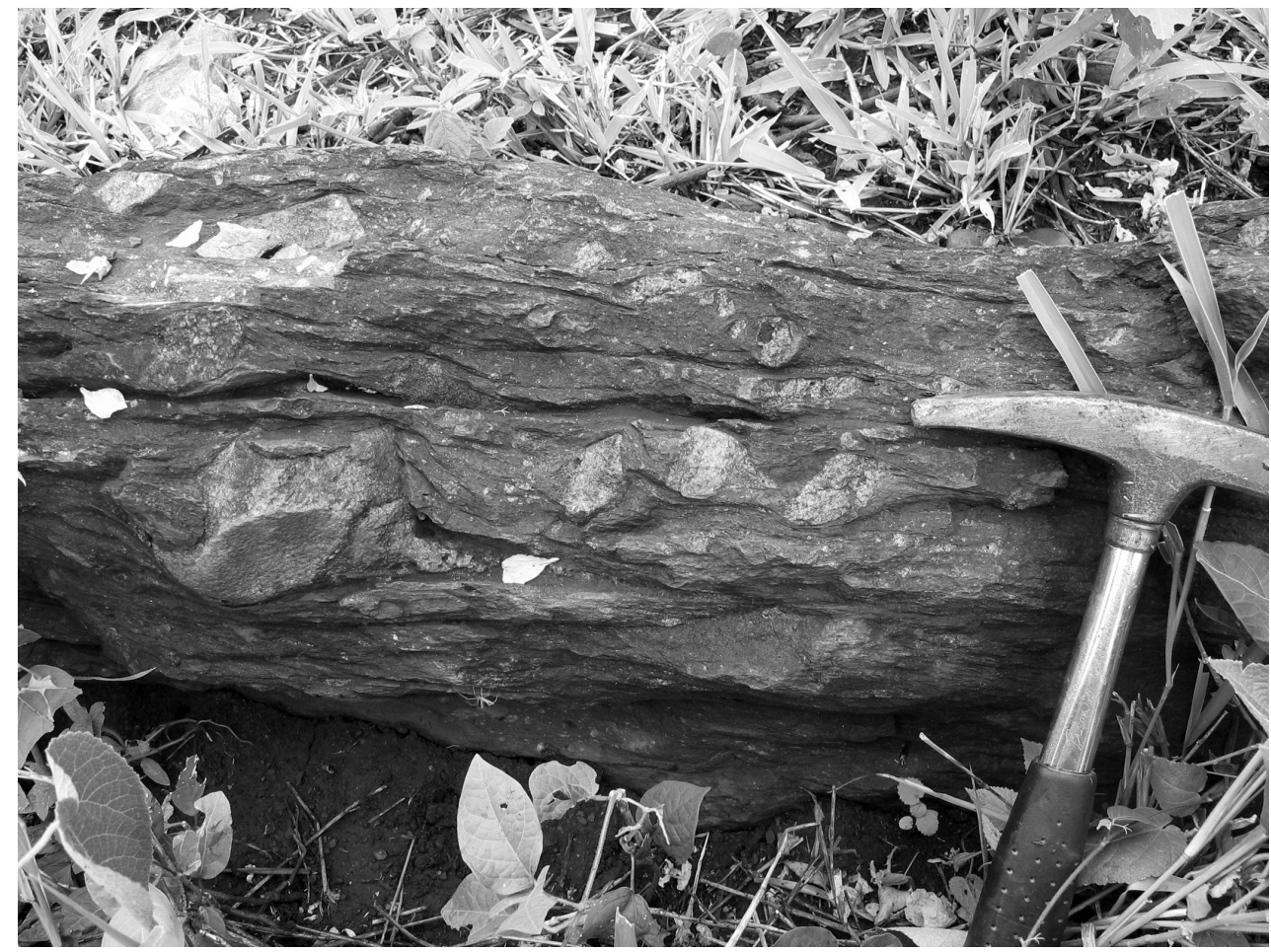

Figura 6 - Aspecto macroscópico de diamictito de matriz ferruginosa contendo clastos centimétricos a decimétricos de gnaisse/quartzito. 


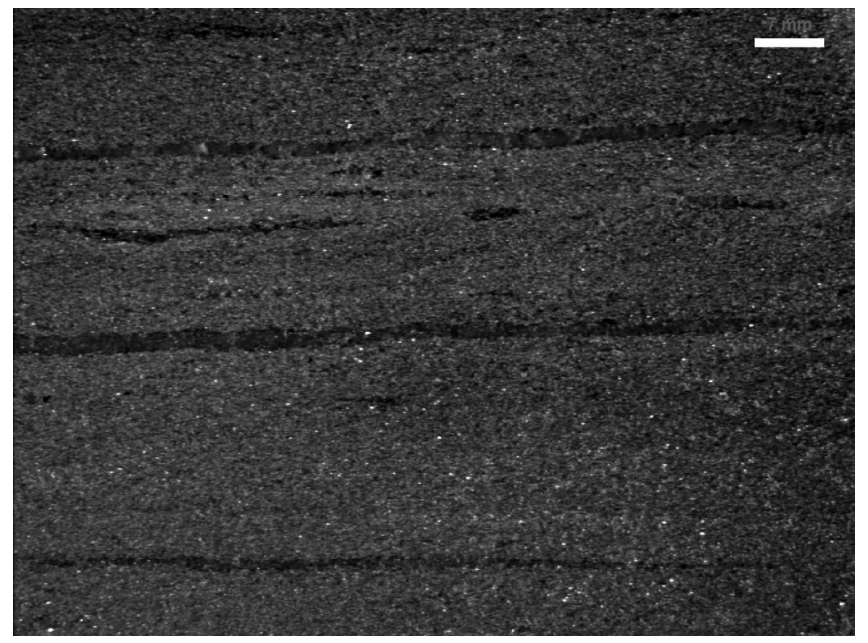

Figura 7 - Aspecto microscópico da formação ferrífera da Fazenda São Manoel. Notar o bandamento destacado pelas finas lâminas de sílica (Escala: $7 \mathrm{~mm}$ ).

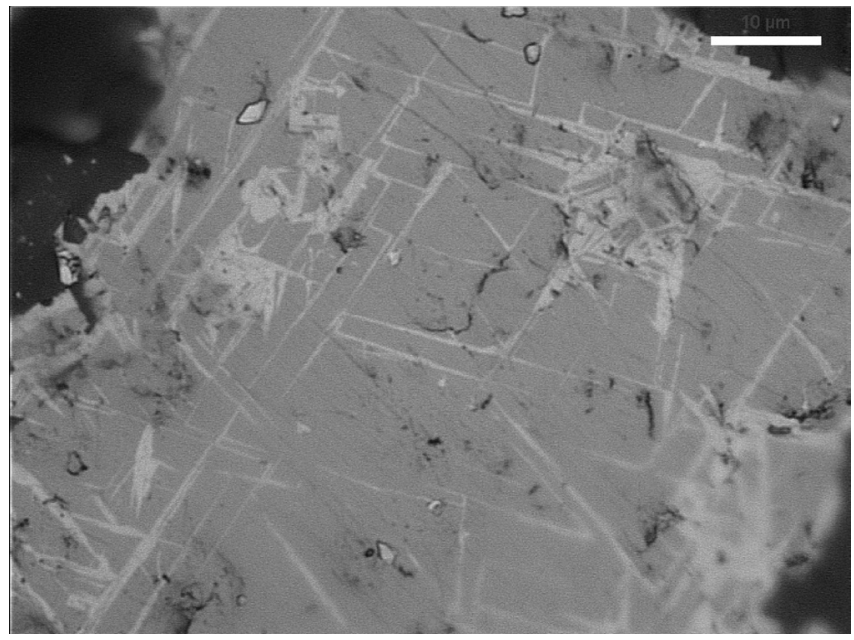

Figura 8 - Fotomicrografia de grão mostrando finas lâminas de hematita ao longo dos planos octaédricos da magnetita (Escala: $10 \mu \mathrm{m}$ ).

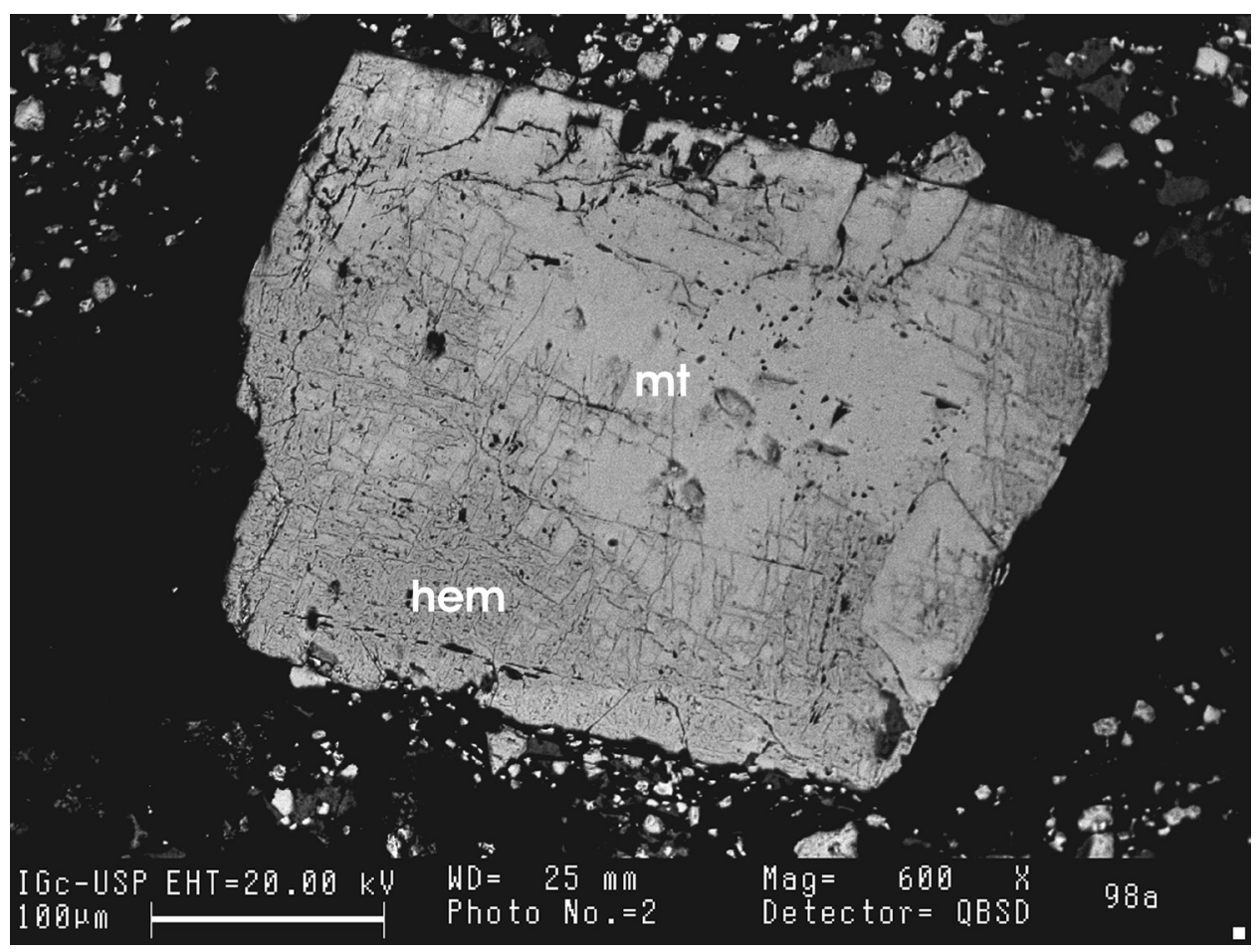

Figura 9 - Grão martitizado. Observar hematita, representada pelas bordas de coloração cinza escura, substituindo a magnetita, preservada no centro do grão

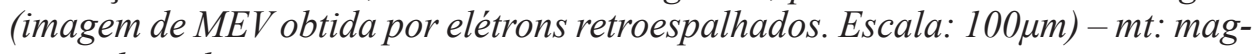
netita, hem: hematita.

ços $\mathrm{Ba}, \mathrm{Co}, \mathrm{Cr}, \mathrm{Cu}, \mathrm{Ni}, \mathrm{Pb}, \mathrm{Rb}, \mathrm{S}, \mathrm{Sr}, \mathrm{V}, \mathrm{Y}, \mathrm{Zn}$ e Zr. A perda ao fogo (PF) foi determinada mediante calcinação da amostra em mufla, a $1.000{ }^{\circ} \mathrm{C}$.

As análises foram realizadas nos Laboratórios do Instituto de Geociências (LABMEV, LABPETRO, Química, FRX e DRX) da Universidade de São Paulo.

CARACTERIZAÇÃO MINERALÓGICA E GEOQUÍMICA DA FORMAÇÃO FERRÍFERA A formação ferrífera da Fazenda São Manoel constitui-se de bandas centimétricas de magnetita/hematita alternadas com lâminas de sílica. Próximo ao centro do corpo, o bandamento torna-se milimétrico. A magnetita e a hematita são os principais constituintes mineralógicos, ocorrendo goethita de forma subordinada. Magnetita também ocorre como relictos no interior dos cristais de martita e hematita. Quartzo e muscovita compõem os demais minerais presentes.

Observa-se a alteração de magnetita para hematita por meio do processo de martitização (Fig. 9) atra- 
Tabela 1 - Análise química por fluorescência de raios $X$ da formação ferrífera. As amostras foram coletadas a intervalos aproximados de $15 \mathrm{~cm}$ da base (9-8A) para o topo (9-8I) da camada. Os valores dos óxidos são em porcentagem e os dos elementos em parte por milhão (ppm).

\begin{tabular}{c|c|c|c|c|c|c|c|c|c|c}
\hline & $9-8 \mathrm{~A}$ & $9-8 \mathrm{C}$ & $9-8 \mathrm{D}$ & $9-8 \mathrm{E}$ & $9-8 \mathrm{~F} 1$ & $9-8 \mathrm{~F} 2$ & $9-8 \mathrm{G}$ & $9-8 \mathrm{H}$ & $9-8 \mathrm{I}$ & LD $(\%)$ \\
\hline $\mathrm{SiO}_{2}$ & 46,81 & 15,86 & 32,02 & 40,82 & 34,92 & 35,78 & 25,66 & 19,82 & 57,74 & 0,03 \\
\hline $\mathrm{Al}_{2} \mathrm{O}_{3}$ & 7,78 & 3,43 & 3,45 & 3,08 & 2,81 & 3,07 & 2,80 & 2,49 & 6,01 & 0,01 \\
\hline $\mathrm{MnO}$ & 0,077 & 0,034 & 0,014 & 0,034 & 0,020 & 0,020 & 0,050 & 0,052 & 0,012 & 0,002 \\
\hline $\mathrm{MgO}$ & 0,77 & 0,35 & 0,32 & 0,25 & 0,26 & 0,31 & 0,30 & 0,25 & 0,65 & 0,01 \\
\hline $\mathrm{CaO}$ & 0,17 & $<0.01$ & 0,14 & 0,04 & $<0.01$ & $<0.01$ & 0,02 & $<0.01$ & 0,02 & 0,01 \\
\hline $\mathrm{Na}_{2} \mathrm{O}$ & $<0.02$ & $<0.02$ & $<0.02$ & $<0.02$ & $<0.02$ & $<0.02$ & $<0.02$ & $<0.02$ & $<0.02$ & 0,02 \\
\hline $\mathrm{K}_{2} \mathrm{O}$ & 2,33 & 1,48 & 1,42 & 1,16 & 1,23 & 1,24 & 1,19 & 1,04 & 2,11 & 0,01 \\
\hline $\mathrm{TiO}_{2}$ & 0,565 & 0,304 & 0,237 & 0,236 & 0,252 & 0,260 & 0,250 & 0,243 & 0,392 & 0,007 \\
\hline $\mathrm{P}_{2} \mathrm{O}_{5}$ & 0,621 & 0,162 & 0,309 & 0,354 & 0,162 & 0,160 & 0,529 & 0,308 & 0,452 & 0,003 \\
\hline $\mathrm{Fe} \mathrm{O}_{3}$ & 38,05 & 76,37 & 61,58 & 52,85 & 57,92 & 58,03 & 66,30 & 73,47 & 31,05 & 0,01 \\
\hline $\mathrm{PF}$ & 2,42 & 0,73 & 0,58 & 1,99 & 1,49 & 1,47 & 2,68 & 2,02 & 2,43 & 0,01 \\
\hline \multicolumn{7}{|l|}{} \\
\hline $\mathrm{T}$
\end{tabular}

vés de finas lâminas de hematita que se formaram ao longo dos planos octaédricos da magnetita (Fig. 8).

Os teores de $\mathrm{Fe}_{2} \mathrm{O}_{3}$ da formação ferrífera apresentam variações (Tab. 1). $\mathrm{Fe}_{2} \mathrm{O}_{3}$ mais $\mathrm{SiO}_{2}$ compõem entre $91,9 \%$ e $93,8 \%$ do total, com teores de $\mathrm{Fe}_{2} \mathrm{O}_{3}$ variando da ordem de $76 \%$ na base e topo do pacote, a $52 \%$ nas porções intermediárias da seção. Os teores de $\mathrm{Al}_{2} \mathrm{O}_{3}(2,89-3,45 \%)$ e $\mathrm{P}_{2} \mathrm{O}_{5}(0,160-0,529 \%)$ são altos quando comparados com outras formações ferríferas (Horstmann \& Hälbich 1995). Teores de $\mathrm{MnO}$ são praticamente nulos, da ordem de $0,010-0,080 \%$, assim como dos demais óxidos medidos $\left(\mathrm{MgO}, \mathrm{CaO}, \mathrm{Na}_{2} \mathrm{O}\right.$ e $\mathrm{TiO}_{2}$ ). Teores da ordem de $2 \%$ para $\mathrm{K}_{2} \mathrm{O}$ ocorrem devido à presença de clastos feldspáticos. Elementos traços medidos ( $\mathrm{Ba}, \mathrm{Co}, \mathrm{Cr}, \mathrm{Cu}, \mathrm{Ni}, \mathrm{Pb}, \mathrm{Rb}, \mathrm{S}, \mathrm{Sr}, \mathrm{V}, \mathrm{Y}, \mathrm{Zn}$ e $\mathrm{Zr}$ ) não apresentaram teores significativos (Tab. 1).

Há forte correlação linear entre $\mathrm{Al}$ e Ti (coeficiente de correlação $[\mathrm{r}]=0,97)$ assim como $\mathrm{Al}$ e $\mathrm{Zr}(\mathrm{r}$ $=0,92)$, e moderada correlação entre $\mathrm{Al}$ e $\mathrm{P}(\mathrm{r}=0,66)$ (Fig. 10), sugerindo, segundo Beukes et al. (1990) e Horstmann \& Hälbich (1995), contribuição detrítica durante a formação dos sedimentos predominantemente químicos. Esta característica também se evidencia pela marcante presença de sedimentos detríticos na formação ferrífera.
Blocos isolados de granito ocorrem em meio à formação ferrífera (Fig. 11), mas a ação tectônica dificulta a observação das relações entre os clastos e o bandamento original. Apesar da deformação, é possível observar o bandamento típico ferrífero/silicoso em algumas porções.

Veios milimétricos de quartzo estirados e ondulados são freqüentes, e evidenciam a remobilização da sílica para o centro da ocorrência durante a deformação, enriquecendo as bordas do corpo com teores médios de $\mathrm{Fe}_{2} \mathrm{O}_{3}$ da ordem de $75 \%$.

Em determinadas porções, a remobilização da sílica foi tão eficaz que concentrou o teor de ferro em até $97 \%$ de $\mathrm{Fe}_{2} \mathrm{O}_{3}$ em bandas centimétricas e maciças (Boggiani et al. 2006).

A ação tectônica também pode ser evidenciada pela recristalização dinâmica de cristais de quartzo, onde a característica microestrutural que os distingue é dada pela recristalização rotacionada dos grãos durante a deformação.

DISCUSSÃO Os registros de formações ferríferas mais antigos conhecidos são os da região de Isua, oeste da Groenlândia, datados de 3,8 Ga e relacionados a núcleos cratônicos arqueanos (Dymek \& Klein 1988). 


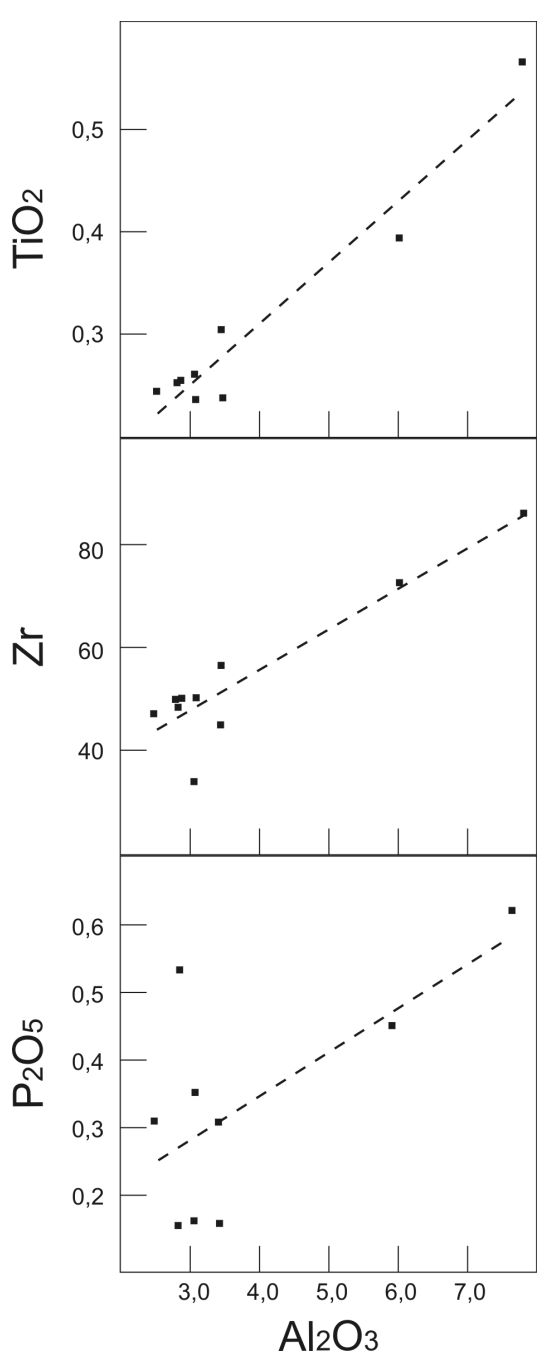

Figura 10 - Correlação interelementar. Notar que $\mathrm{Al}_{2} \mathrm{O}_{3}$ correlaciona-se muito bem com $\mathrm{TiO}_{2}$ e $\mathrm{Zr}$, e de forma moderada com $\mathrm{P}_{2} \mathrm{O}_{5}$, sugerindo a participação de componentes detriticos durante a deposição.

Outros exemplos arqueanos ocorrem associados a seqüências do tipo greenstone belt, com idades entre 3,5 a 2,5 Ga, nos quais se inserem as ocorrências do Grupo Nova Lima de Minas Gerais (Dorr II 1969). O registro das maiores ocorrências (em tamanho e volume de depósito) ocorre a aproximadamente $2,5 \mathrm{Ga}$, devido ao tamanho das bacias de Hamersley, na Austrália, situado entre 2,6 a 2,45 Ga (Trendall \& Blockley 1970), assim como de Transvaal, na África do Sul, de idade aproximada entre 2,5 a 2,3 Ga (Klein \& Beukes 1989). Associados a esse intervalo de tempo encontram-se os depósitos brasileiros do Grupo Itabira, no Quadrilátero Ferrífero, e Grão Pará, na Serra dos Carajás.

É marcante a interrupção da deposição ferrífera por volta de $1,8 \mathrm{Ga}$, com o retorno das ocorrências destas formações no Neoproterozóico, entre 0,8 e 0,6 Ga, geralmente associadas a depósitos glaciais (Trendall \& Blockley 2004). Na Fig. 12 encontra-se representada a distribuição relativa das ocorrências conhecidas com relação ao volume dos depósitos australianos de Hamersley (Trendall 2002, Klein 2005).

As formações ferríferas do intervalo de tempo compreendido entre 3,8 e 1,8 Ga são mineralógica e quimicamente similares, constituídas por hematita, magnetita, sílica e carbonatos, mais comumente siderita, e membros da série dolomita-anquerita, localmente pirita, e outros minerais indicativos de condições anóxicas durante a deposição. A origem do $\mathrm{Fe}$ e $\mathrm{Si}$, interpretada com base em dados isotópicos do sistema $\mathrm{Sm}-\mathrm{Nd}$ e Elementos Terras Raras, estaria relacionada a fontes vulcânicas (Fryer 1983, Klein \& Beukes 1989, Gross 1991, Klein \& Ladeira 2004) pela presença de atividade ígnea associada. Aproximadamente $20 \%$ do Grupo Hamersley, da Austrália, é constituído por rochas ígneas (Trendall \& Blockley 1970). Porém, não há evidência geológica segura capaz de vincular o depósito desse Grupo a um centro vulcânico específico. Além disso, outras ocorrências, como as do Quadrilátero Ferrífero, não possuem rochas vulcânicas intimamente associadas com as formações ferríferas.

As ocorrências neoproterozóicas são mineralogicamente mais simples e consistem basicamente em hematita e sílica, e, subordinadamente, carbonatos.

De acordo com a hipótese Snowball Earth (Hoffman et al 1998), os BIFs neoproterozóicos surgiram em conseqüência do acúmulo de Fe dissolvido nos oceanos, isolados da atmosfera por espessa camada de gelo que recobriu a Terra. A precipitação das formações ferríferas, de acordo com o mencionado modelo, teria se dado após o degelo, com a mistura de águas ricas em Fe dissolvido com águas oxigenadas, provavelmente por meio de circulações oceânicas associadas a correntes ascendentes (Kirschvink 1992).

Gross (1973) acreditava que a atividade das fumarolas seria a principal fonte do ferro. Yeo (1981) em estudo estratigráfico, sedimentológico e geoquímico detalhado na formação ferrífera Rapitan, chegou à mesma conclusão. O mesmo autor concluiu ainda que a precipitação química de ferro e sílica estava diretamente relacionada a correntes ascendentes de salmouras ricas em ferro, formada pela atividade hidrotermal. Estas salmouras resfriadas pela presença das geleiras se precipitariam em águas profundas. Uma interpretação similar em estudo sedimentológico e geoquímico detalhado foi formulada no sudoeste africano (Breitkopf 1988).

Young (2002) questionou a relação genética entre os BIFs como evidência da hipótese Snowball Earth em função das ocorrências de formações ferríferas serem relativamente menos abundantes do que os depósitos glaciais. Exemplificou ainda que, no caso do Grupo Rapitan, um dos depósitos de ferro neoproterozóico mais conhecido, a alta proporção de sedimentos ricos em ferro ocorre em argilitos no topo da Formação Sayunei, subjacente ao espesso pacote de diamictito (Young 1976, Klein \& Beukes 1993), o que demonstraria que as formações ferríferas se depositaram antes da formação da cobertura de gelo e, assim, não poderia ser 


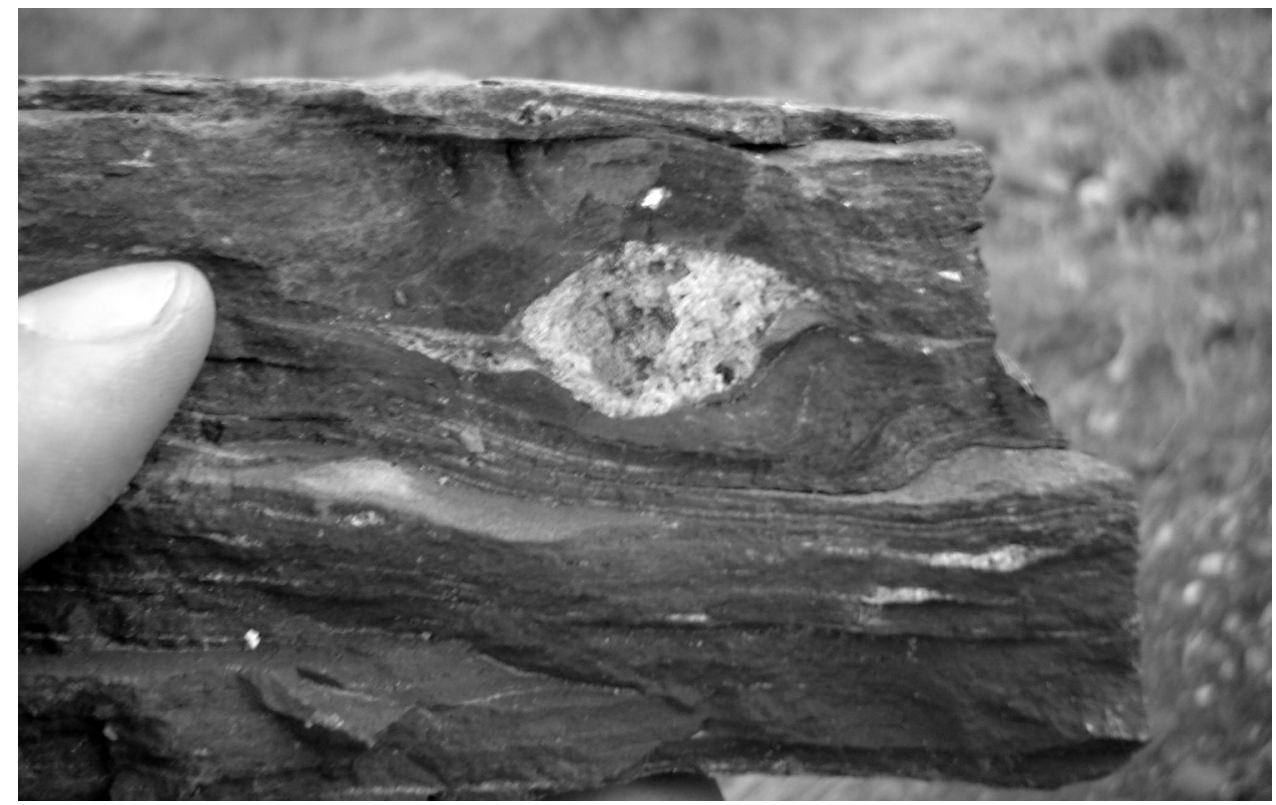

Figura 11 - Formação ferrifera com seixo de granito imerso. A foliação tectônica não permite visualizar os contatos originais entre o seixo e a laminação subjacente.

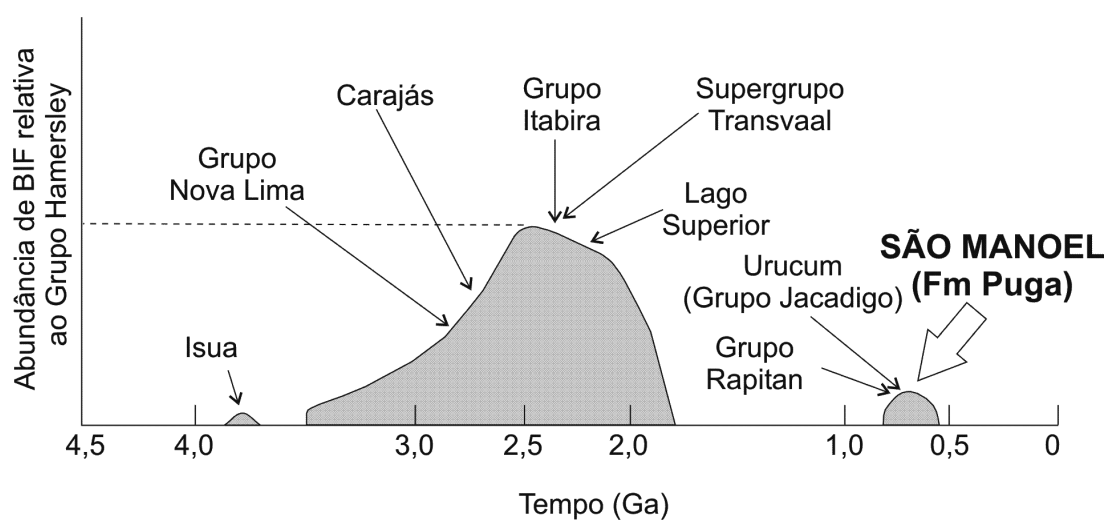

Figura 12 - Abundância esquemática de formação ferrífera através do Pré-Cambriano (modificado de Klein 2005). O tempo decorre da esquerda para a direita, e os números mostram bilhões de anos $(G a)$ antes do presente. O eixo das ordenadas, não quantificado, representa uma estimativa subjetiva de abundância, relativa ao volume dos depósitos do Grupo Hamersley. No destaque a ocorrência estudada no presente trabalho (Fazenda São Manoel) situada entre depósitos do Neoproterozóico.

atribuída à oxigenação pós-glaciação.

A inexistência de ambientes modernos de formação de BIFs dificulta a formulação de modelos genéticos, de tal forma que não há consenso sobre os mecanismos de precipitação, gênese do bandamento, influência de processos biológicos assim como a proveniência do ferro.

O modelo clássico de interpretação dos mesmos por aumento do teor de oxigênio nos oceanos, devido à proliferação de organismos fotossintetizantes, formulado por Cloud (1973), tem sido questionado frente às recentes datações radiométricas dos depósitos paleoproterozóicos, as quais demonstram que os mesmos teriam sido depositados em amplo intervalo de tempo, por volta de 50 milhões de anos, e não de forma relativamente instantânea, como admitido pelo referido modelo (Trendall 2002). Alternativamente, modelos de precipitação abiogênica (Trendall 2002) têm sido formulados: a ausência de carbono orgânico nas formações ferríferas tem sido um argumento contrário à associação de atividade microbiana fotossintetizante a este tipo de deposição (Klein \& Beukes 1989).

Três condições básicas para o sítio deposicional têm sido apontadas como necessárias para a deposição 
de formação ferrífera: estabilidade tectônica por período de aproximadamente um milhão de anos, suficiente profundidade e geometria do corpo d'água que permita a livre circulação do ferro dissolvido, acrescida ainda da existência de fitoplancton (Trendall 2002). Essas premissas têm por base a relativa ausência de material epiclástico na maioria das formações ferríferas conhecidas, com raras exceções como os BIFs do Grupo Jacadigo, no Maciço de Urucum, onde ocorrem inúmeras intercalações de arcóseos entre os pacotes de formações ferríferas (Almeida 1946, Dorr II 1945, Urban et al. 1992, Trompette et al. 1998).

Os dados isotópicos do sistema $\mathrm{Sm}-\mathrm{Nd}$ e Elementos Terras Raras são consistentes com a derivação do ferro das formações ferríferas a partir de fontes vulcânicas (Fryer 1983, Klein \& Beukes 1989, Gross 1991). Porém, esta interpretação não é excludente em relação às hipóteses de origem glacial, global ou não, ou com os modelos de bacias riftes com influência glacial (Young 2002), o que pode ser um modelo apropriado para os depósitos do Maciço de Urucum (Dardenne 1998).

No caso da formação ferrífera de Bodoquena, uma única ocorrência tectonicamente deformada, dificulta o entendimento das relações estratigráficas e sedimentológicas não sendo possível uma interpretação segura. Os diamictitos associados à formação ferrífera encontram-se também deformados e não foram observadas evidências claras da deposição glacial, de tal forma que a hipótese de deposição através de processos de fluxos gravitacionais sem a influência do gelo não pode ser descartada.

Embora ocorram rochas metabásicas nas proximidades da Fazenda São Manoel, descritas originalmente por Nogueira et al. (1978), as relações de contato entre essas rochas e os metassedimentos ainda não foram estabelecidas, não sendo possível associá-las à gênese dos BIFs.

CONCLUSÕES A ocorrência da Fazenda São Manoel consiste de uma formação ferrífera, com alternância de bandas de hematita e sílica, em parte estiradas devido às deformações tectônicas da Faixa Paraguai.
Essa formação ferrífera ocorre como camada de $2 \mathrm{~m}$ de espessura, limitada, por contato brusco no topo e na base por diamictito de matriz ferruginosa da Formação glaciogênica Puga. Os teores de $\mathrm{Fe}_{2} \mathrm{O}_{3}$ na camada de BIF variam de $76 \%$, na base e topo do pacote, a $52 \%$ nas porções intermediárias. Lâminas milimétricas de sílica evidenciam a remobilização da sílica para o centro da ocorrência durante a deformação, o que promoveu o enriquecimento em Fe nas bordas do corpo. Em determinadas porções, a remobilização foi tão eficaz, concentrando o teor de ferro em até $97 \%$ de $\mathrm{Fe}_{2} \mathrm{O}_{3}$ devido, provavelmente, a ação tectônica.

Os teores de $\mathrm{Al}_{2} \mathrm{O}_{3}$ e $\mathrm{P}_{2} \mathrm{O}_{5}$ são relativamente elevados quando comparados com outras formações ferríferas, devido à contribuição detrítica observada nos sedimentos predominantemente químicos.

A presença de clastos isolados de granito, de dimensões centimétricas a métricas, imersos em meio à formação ferrífera não é conclusiva para associá-los a sedimentação glacial devido à obliteração causada no bandamento original pela ação tectônica.

Apesar dos diamictitos da Formação Puga terem sua origem relacionada a eventos glaciogênicos, provavelmente Marinoano, não foram encontradas evidências seguras que permitissem relacionar a origem das formações ferríferas aqui descritas a estes eventos.

Agradecimentos O presente artigo é produto de projeto de pesquisa financiado pela Fundação de Amparo à Pesquisa do Estado de São Paulo (FAPESP processo 04/01233-0) e vinculado ao Projeto IGCP-478 "Neoproterozoic to Early Palaeozoic Paleogeographic, Palaeoclimatic, Palaeobiologic and Tectonomagmatic events within the Framework of SW-Gondwana". Contamos ainda com apoio da Mineração Horii, à qual agradecemos na pessoa de Kazuto Horii. Os autores agradecem ao $\mathrm{CNPq}$ pelas bolsas de produtividade à pesquisa e o primeiro autor pela bolsa de mestrado da FAPESP (Processo 06/58566-6). Aos professores João B. Moreschi e Gianna Garda do IG-USP, pelas discussões nas diversas etapas do trabalho, aos funcionários da Fazenda São Manoel pelo apoio durante as atividades de campo e aos revisores da RBG pelas sugestões ao manuscrito.

\section{Referências}

Almeida F.F.M. 1946. Origem dos minérios de Ferro e Manganês de Urucum. Boletim da Divisão de Geologia e Mineralogia, DNPM, 119:1-58.

Almeida F.F.M. 1965. Geologia da Serra da Bodoquena (Mato Grosso), Brasil. Boletim da Divisão de Geologia e Mineralogia, DNPM, 219:1-96.

Alvarenga C.J.S., Moura C.A.V., Gorayeb P.S.S., Abreu, F.A.M. 2000. Paraguay and Araguaia belts. In.: U.G. Cordani, E.J. Milani, A.Thomas Filho, D.A. Campos (eds.) Tectonic Evolution of South América. International Geological Congress, 31, Rio de Janeiro, p: 183-193.

Alvarenga C.J.S., Santos R.V., Dantas E.L. 2004. C-O-Sr isotopic stratigraphy of cap carbonates overlying Ma- rinoan-age glacial diamictites in the Paraguay Belt, Brazil. Precambrian Research, 131:1-21.

Alvarenga C.J.S. \& Trompette R. 1992. Glacially influenced sedimentation in the later Proterozoic of the Paraguay Belt (Mato Grosso, Brazil). Palaeogeography, Palaeoclimatology, Palaeoecology, 92:85-105.

Beukes N.J. 1973. Precambrian iron-formations of southern Africa. Economic Geology, 68: 960-1004.

Beukes N.J., Klein C., Kaufman A.J., Hayes J.M. 1990. Carbonate petrography, kerogen distribution, and carbon and oxygen isotope variations in an early Proterozoic transition from limestone to iron-formation depositon, Transvaal Supergroup, South Africa. Economic Geol- 
ogy, 85(4):663-690.

Boggiani P.C. 1998. Análise Estratigráfica da Bacia Corumbá (Neoproterozóico) - Mato Grosso do Sul. Tese de Doutoramento, Instituto de Geociências, USP, 181p.

Boggiani P.C. \& Coimbra A.M. 1996. The Corumbá Group (Central South America) in the context of Late Neoproterozoic Global Changes. Anais da Academia Brasileira de Ciências, Resumo das Comunicações, 68(4):595596.

Boggiani P.C., Ferreira V.P., Sial A.N., Babinski M., Trindade R.I.F., Aceñolaza G., Toselli A.J., Parada M.A. 2003. The cap carbonate of the Puga Hill (Central South America) in the context of the post-Varanger Glaciation. In: South American Symposium on Isotope Geology,4, Short Papers, Salvador, Brasil, v. 1, p. 324- 327.

Boggiani P.C., Babinski M., Yamamoto J.K., Fairchild T.R., Riccomini C., Diratgitch A.A., Liu D. 2005. U-Pb SHRIMP investigation of ash beds in the Corumbá Group (Ediacaran), Paraguay Belt, Brazil. In: 2 Symposium on Neoproterozoic - Early Palaeozoic Events in southwestern Gondwana, 2, Windhoek - Namibia, $A b$ stracts, IGCP-478, p. 8-9.

Boggiani P.C., Piacentini T., Fairchild T.R., Yamamoto J.K., Campanha G.A. C., SÁ F.R., Zuquim M. P.S. 2006. Banded Iron Formation (BIF) associated with glacial sediments of the Puga Formation (Marinoan) in the Serra da Bodoquena (Mato Grosso do Sul, Brazil). In: South American Symposium on Isotope Geology, 5 (IGCP478, Meeting), Punta del Este, Uruguay, Short Papers, p. 227-229.

Breitkopf J.H. 1988. Iron formations related to mafic volcanism and ensialic rifting in the southern margin zone of the Damara orogen, Namibia. Precambrian Research, 38:111-130.

Cloud P. 1973. Paleoecological significance of the banded iron-formation. Economic Geology, 68:1135-1143.

Corrêa J.A., Correia Filho F.C.L., Scislewski G., Neto C., Cavallon L.A., Cerqueira N.L.S., Nogueira V.L. 1979. Geologia das regiões centro e oeste de Mato Grosso do Sul. Projeto Bodoquena. DNPM, Série Geológica Básica $\mathrm{n}^{\circ}$ 3, mapa geológico. Escala 1:250.000.

Dantas E.L. \& Martinelli C.C. 2003. Nd isotopes from the Araés Metavocano-sedimentary sequence in the Paraguay Belt, Nova Xavantina, Mato Grosso, Central Brazil. In: South American Symposium on Isotope Geology, 4, Short Papers, Salvador, Brasil, v. 1, p.168-169.

Da Rosa A.A.S., Pinho F.E., Gheler W.L. 1997. Formações ferríferas no Grupo Cuiabá, Neoproterozóico (?), MT. In: Simpósio de Geologia do Cento-Oeste, Anais. Cuiabá, MT, p. 99-102.

Dardenne M.A. 1998. Modelo Hidrotermal Sedimentar Exalativo para os Depósitos Fe-Mn da Região de Corumbá, Mato Grosso do Sul. In: SBG, Congresso Brasileiro de Geologia, 40, Belo Horizonte, Anais, p. 152.

Delgarno C.R. \& Johnson J.E. 1965. The Holowilena ironstone, a Sturtian glacigene unit. South Australia Geological Survey, Geological Notes, 11:3-4.

Dorr II J.V.N. 1945. Manganese and iron deposits of Morro do Urucum, Mato Grosso, Brazil. Bulletin U.S. Geological Survey, 946A, 47 p.
Dorr II J.V.N. 1969. Physiographic, stratigraphic and structural development of the Quadrilátero Ferrifero, Minas Gerais, Brazil. U.S. Geological Survey Professional Paper, vol. 641A, 110p.

Dymek R.F. \& Klein C. 1988. Chemistry, petrology and origin of banded iron formation lithologies from the 3.800 Ma Isua Supracrustal Belt, West Greenland. Precambrian Research, 39:247-302

Fryer B.J. 1983. Rare earth elements in iron-formation. In: Trendall A.F. \& Morris R.C. (eds.) Iron-formation: facts and problems. Amsterdam, Netherlands, Elsevier, p. 345-358.

Gaucher C., Boggiani P.C., Sprechmann P., Sial A. N., Fairchild T.R. 2003. Integrated correlation of Vendian to Cambrin Arroyo del Soldado and Corumbá Groups (Uruguay and Brazil): palaeogeographic, palaeoclimatic and palaeobiologic implactions. Precambrian Research, 120(3-4):241-278.

Godói H.O. 2001. Aquidauna. Folha SF.21-X-A. (Estado de Mato Grosso do Sul). Programa Levantamentos Geológicos Básicos do Brasil, Brasília, CPRM, Escala 1:250.000.

Gross G.A. 1973. The depositional environment of principal types of Precambrian iron-formations. In: UNESCO (ed.) Genesis of Precambrian iron and manganese deposits. Proceedings of the Kiev Symposium, 20-25 August 1970, Earth Sciences, 9, p. 15-21.

Gross G.A. 1991. Geochemical data on iron-formations. In: G.A. Gross \& J.A. Donaldson (eds.) Iron-formation and metalliferous sediments in central Canada. Geological Survey of Canada, p. 57-59.

Hahn G., Hahn R., Pflug H.D., Leonardos O.H., Walde D.A.G. 1982. Körpelich erhaltene scyphozoen - reste aus dem Jungpräkambrium Brasiliens. Geologica et Paleontologica, 16:1-18.

Hoffman P.F., Kaufman A.J., Halverson G. P., Schrag D. P. 1998. A Neoproterzoic snowball Earth. Science, 281:1342-1346.

Horstmann U.E. \& Hälbich I.W. 1995. Chemical composition of banded iron-formation of the Griqualand West Sequence, Northern Cape Province, South Africa, in comparison with other Precambrian iron formations. Precambrian Research, 72:109-145.

Kendall B.S., Craeser R.A., Ross G.M., Selby D. 2004. Constraints on the timing of Marinoan "Snowball Earth" glaciation by ${ }^{187} \mathrm{Re}-{ }^{187} \mathrm{Os}$ dating of a Neoproterozoic, post-glacial black shale in western Canada. Earth and Planetary Science Letters, 222:729-740.

Kirschvink J.L. 1992. Late Proterozoic Low-Latitude Global Glaciation: the Snowball Earth. In: J.W. Schopf \& C. Klein (eds.). The Proterozoic Biosphere - A Multidisciplinary Study. Cambridge, p. 51-52.

Klein C. 2005. Some Precambrian banded iron-formation (BIFs) from around the world: their age, geologic setting, mineralogy, metamorphism, geochemistry, and origin. American Mineralogist, 90:1473-1499.

Klein C. \& Beukes N.J. 1989. Geochemistry and sedimentology of a facies transition from limestone to iron-formation deposition in the Early Proterozoic Transvaal Supergroup, South Africa. Economic Geology, 84:1733-1774. 
Klein C. \& Beukes N.J. 1993. Sedimentology and geochemistry of the glaciogenic late Proterozoic Rapitan ironformation, in Canada. Economic Geology, 88:542-565.

Klein C. \& Ladeira E.A. 2004. Geochemistry and Mineralogy of Neoproterozoic Banded Iron-Formations and some selected, Siliceous Manganese Formations from the Urucum District, Mato Grosso do Sul, Brazil. Economic Geology, 99:1233-1244.

Lacerda Filho J.V., Brito R.S.C., Silva M.G., Oliveira C.C., Moreton L.C., Martins E.G., Lopes R.C., Lima T.M., Larizzatti J.H., Valente C.R. 2006.Geologia e Recursos Minerais do Estado de Mato Grosso do Sul. CPRM-SEPROTUR/MS, texto explicativo dos mapas geológicos e de recursos minerais do Estado de Mato Grosso do Sul, Escala 1:1.000.000, Campo Grande, 121p.

Martin H. 1978. The mineralization of the ensialic Damara orogenic belt. South Africa Geological Survey, Special Publication, 4:405-415.

Miller J.M.G. 1985. Glacial and syntectonic sedimentation: The upper Proterozoic Kingston Peak Formation, southern Panamint Range, eastern California. Geological Society America Bulletin, 96:1537-1553.

Nogueira A.C.R., Riccomini C., Sial A.N., Moura C., Fairchild T.R. 2003. Soft-sediment deformation at the base of the Neoproterozoic Puga cap carbonate (southwestern Amazon Craton, Brazil): Confirmation of rapid icehouse-greenhouse transition in snowball earth. Geology, 31(7):613-616.

Nogueira V.L., Oliveira C.C., Figueiredo J.A., Corrêa Filho F.C.L., Scislewski G., Souza M.R., Moraes Filho J.C.R., Leite E.A., Souza N.B., Souza J.O., Cerqueira N.L.S., Vanderlei A.A., Takaschi A.T., Abreu Filho W., Rosito J., Olivatti O., Hausen J.E.P., Gonçalves G.N.D., Ramalho R., Pereira L.C.B. 1978. Projeto Bonito - Aquidauana, relatório final. Goiânia, DNPM / CPRM, 14v. (Relatório de Arquivo Técnico do DGM, 2744 p.).

Piacentini T., Boggiani P.C., Yamamoto J.K. 2006. Formação Ferrífera Bandada Associada à Formação Glacial Puga na região da Bodoquena, MS. In: Congresso Brasileiro de Geologia, 43, Aracajú-SE. Anais, p. 155.

Pinho F.E. 1990. Geoquímica do depósito de ouro de Nova Xavantina - leste do Estado de Mato Grosso. In: SBG, Congresso Brasileiro de Geologia, 36, Natal-RN, Anais, v. 3, p. 1316-1330.

Trendall A.F. 1973. Iron-formations of the Hamersley Group of Western Austrália: examples of varyed Precambrian evaporates. In: UNESCO (ed.) Genesis of Precambrian iron and manganese deposits. Proceedings of the Kiev Symposium, 20-25 August 1970, Earth Sciences, 9, p. 377-380.

Trendall A.F. 2002. The significance of iron-formation in the Precambrian stratigraphic record. In: W. Alteramann \& P. L. Corcoran (eds.) Precambrian Sedimentary Environments: A Modern Approach to Ancient Depositional Systems. Special Publication n.33 of the IAS, Blacwell Science, p. 33-66.

Trendall A.F. \& Blockley J.G. 1970. The Iron-Formations of the Precambrian Hamersley Group, Western Austra- lia. Geological Survey of Western Australia Bulletin, 119:366.

Trendall A.F. \& Blockley J.G. 2004. Precambrian iron-formation. In: P.G. Eriksson, W. Alteramann, D.R. Nelson, Mueller W.U., O. Catuneanu (eds.) The Precambrian Earth: tempos and events. Developments in Precambrian Geology, Elsevier, 12:403-421.

Trindade R.I.F., Font E., D’Agrella Filho M.S., Nogueira A.C.R., Riccomini, C. 2003. Low-latitude and multiple geomagnetic reversals in the Neoporterozoic Puga cap carbonate, Amazon craton. Terra Nova, 15(6):441-446.

Trompette R. 1981. Late Precambrian tillites of the Volta basin and the Dahoneyides orogenic belt (Benin, Ghana, Niger, Togo and Upper Volta). In: M.J. Hmabrey \& W.B. Harland (eds.) Earth's pre-Pleistocene glacial record. Cambridge, Cambridge University Press, p.745-748.

Trompette R., Alvarenga C.J.S., Walde D. 1998. Geological evolution of the Neoproterozoic Corumbá graben system (Brazil). Depositional context of the stratified Fe and Mn ores of the Jacadigo Group. Journal of South America Earth Sciences, 11(6):587-597.

Urban H., Stribrny B., Lippolt H. 1992. Iron and manganes deposits of the urucum district, Mato Grosso do Sul, Brazil. Economic Geology, 87:1375-1392.

Vilela O.V. 1986. As jazidas de minério de ferro dos municípios de Porteirinha, Rio Pardo de Minas, Riacho dos Machados e Grão-Mogol, norte de Minas Gerais. In: Schobbenhaus C. \& Coelho C.E.S. Principais Depósitos Minerais do Brasil: Ferro e Metais da Indústria do Aço, 2:111-120.

Yeo G.M. 1981. The Late Proterozoic Rapitan glaciation in the northern Cordillera. In: F.H.A. Campbell (Editor). Proterozoic Basins of Canada. Geological Survey of Canada, Paper, 81(10):25-46.

Yeo G.M. 1986. Iron formation in the Late Proterozoic Rapitan Group, Yukon and Northwest Territories. Canadian Institute of Mining and Metallurgy, Special Volume, 37:142-153.

Young G.M. 1976. Iron formation and glaciogenic rocks of the Rapitan Group, Northwest Territories Canada. Precambrian Research, 3:137-158.

Young G.M. 1982. The Late Proterozoic Tindir Group, eastcentral Alaska: Evolution of a continental margin. Geological Society of America Bulletin, 93:759-783.

Young G.M. 2002. Stratigraphic and tectonic settings of Proterozoic galciogenic rocks and banded iron-formations: relevance to the snowball Earth debate. Journal of African Earth Sciences, 35:451-466.

Zaine M.F. \& FairchildT.R. 1987. Novas considerações sobre os fósseis da Formação Tamengo, Grupo Corumbá, SW Brasil. In: Sociedade Brasileira de Paleontologia, Congresso Brasileiro de Paleontologia, 10, Resumo das Comunicações, Rio de Janeiro, p. 54.

Manuscrito AE-071/2006 Submetido em 09 de janeiro de 2007 Aceito em 22 de agosto de 2007 